\title{
Double Spiros
}

\section{Key words}

fluorescence

oxidative

cyclization

spirocycles
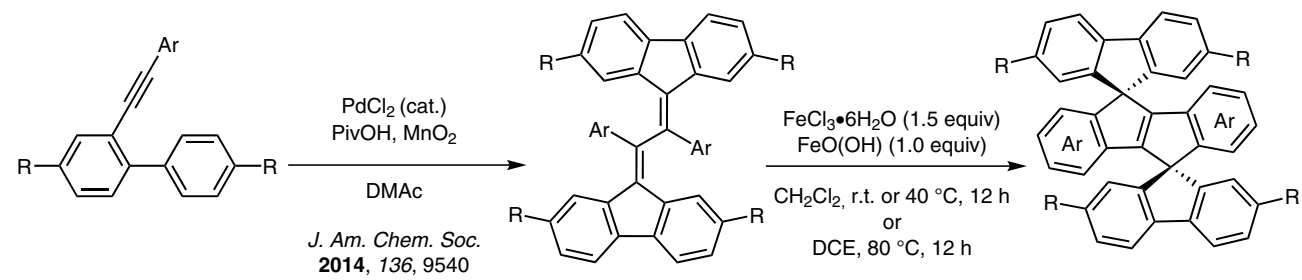

2014, 136, 9540

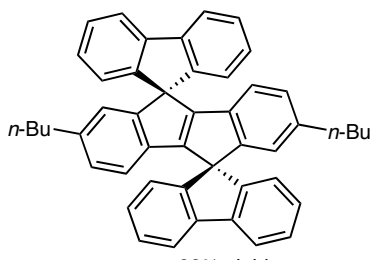

$99 \%$ yield

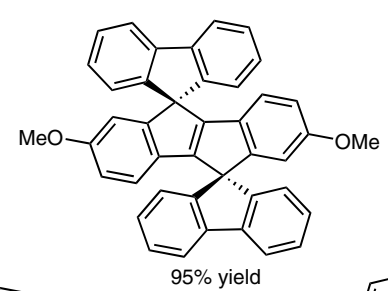

$95 \%$ yield

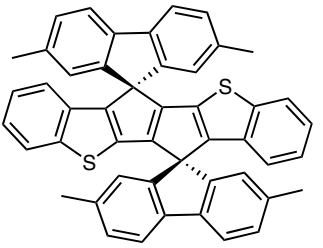

$95 \%$ yield<smiles></smiles>

$97 \%$ yield

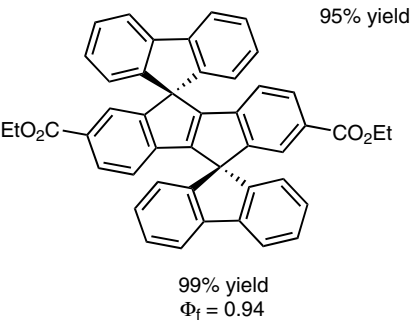

Significance: Spirocyclic compounds containing a fluorene unit have been shown to serve as efficient hole-transporting and light-emitting materials. Synthesis of new structures of this class is therefore interesting and potentially useful for the development of organic optoelectronic devices. In this report the authors describe an efficient synthesis of the dispiro[fluorene-9,5'-indeno[2,1-a]indene-10', 9'"-fluorene] structure through an ironmediated oxidative cyclization process of a fluorene-substituted diene derivative, which can be easily accessed from simple precursors by using a method that was developed by the same group.
Comment: Careful screening of the iron oxidant and additive led to the identification of the optimal conditions under which excellent yields were obtained for substrates containing a variety of common functional groups. The desired product was also found by using other oxidants such as copper(II) chloride and DDQ; however, no yield was obtained when $\mathrm{AlCl}_{3}$ was used. It is proposed that the reaction proceeds via a dication intermediate that is generated upon two-electron oxidation of the diene by the oxidant. One of the spirocyclic compounds displays promising fluorescence properties with an excellent quantum yield. 